\section{"Empathy Intensity" in Early Childhood: Classified Intensity of Emotion During Empathy Situations}

\section{Abstract}

This article examined intensity of emotion in children while reacting to empathy situations. It aimed to reveal a connection between children's intensity of emotion in regard to empathy situations and their ability to explain emotions and their choice of empathetic behavior.

Two theoretical sources were chosen to examine this subject. The first and major is the accumulating knowledge of empathy in children, and the second is the closest term to describe the intensity of emotion - self-regulation. The ability to respond to the ongoing demands of experience with the range of emotions in a manner that is socially tolerable and sufficiently flexible to permit spontaneous reactions as well as the ability to delay spontaneous reactions as needed.

This study examined the intensity of emotions of children regarding empathy situations, and the connection between the intensity of emotions and the child's willingness to act in situations that arouse empathy.

This study concentrated on Empathy Intensity. It tried to classify Empathy Intensity during empathy situations. It also looked for connections between Empathy Intensity and other parts of empathy with hope that Empathy Intensity could shed light on the knowledge about the mechanisms underlying empathic feelings during empathy situations.

Keywords: Empathic; Early childhood; Emotion; Empathy situations

\section{Gila Russo-Zimet ${ }^{1 *}$, Niva Wengrowicz ${ }^{2}$ and Rachel Sagee $^{3}$}

\author{
${ }^{1}$ Early Childhood Research Center, Levinsky \\ College of Education, Tel-Aviv Israel, Israel \\ ${ }^{2}$ Research and Development Authority, \\ Levinsky College of Education, Tel-Aviv \\ Israel, Israel \\ ${ }^{3}$ Levinsky College of Education, Bar-Ilan \\ University, Tel-Aviv Israel, Israel
}

\section{*Corresponding author: Gila Russo-Zimet \\ ”gzimet@zahav.net.il}

Head of Early Childhood Research Center, Levinsky College of Education, 15 Shoshana Persitz st., Tel-Aviv Israel, Israel.

Tel: $972-544547300$

Citation: Russo-Zimet G, Wengrowicz N, Sagee R (2018) "Empathy Intensity" in Early Childhood: Classified Intensity of Emotion During Empathy Situations. J Child Dev Disord. Vol.4 No.4:12

\section{Introduction}

This article examined intensity of emotion in children while reacting to empathy situations.

Two theoretical sources were chosen to examine this subject. The first and major is the accumulating knowledge of empathy in children, and the second is the closest term to describe the intensity of emotion - self-regulation. This is a part of the broader set of emotion-regulation processes, which include the regulation of one's own feelings and the regulation of other people's feelings.

Emotional Regulation can be defined as extrinsic and intrinsic processes responsible for monitoring, evaluating, and modifying emotional reactions $[1,2]$. It is the ability to respond to the ongoing demands of experience with the range of emotions in a manner that is socially tolerable and sufficiently flexible to permit spontaneous reactions as well as the ability to delay spontaneous reactions as needed [3].

Empathy is the ability to identify with another's emotions and understand what they feel $[4,5]$. Empathy Intensity is the capacity to share the feelings of others and take prosocial action. In other words, empathy intensity is the 'level', the 'strength', the 'magnitude', or the 'energy' of a feeling during empathy situations.

This study examined the intensity of the emotions of children who participated in the research regarding empathy situations, and whether there was a connection between the intensity of 
emotions and the child's willingness to act in situations that arouse empathy.

This study concentrated on Empathy Intensity. It tried to classify the Empathy Intensity during empathy situations. It also looked for connections between Empathy Intensity and other parts of empathy with hope that the Empathy Intensity could shed light on the knowledge about the mechanisms underlying empathic feelings during empathy situations. Before presenting the main questions, the next section will examine the literature on empathy.

\section{Empathy}

Empathy, the vicarious sharing of the emotions of others, is widely regarded as one of the main psychological motivators of understanding of the other $[6,7]$. Empathizing with the suffering of another can provide the emotional impulse to engage in helpful acts meant to alleviate the other person's suffering and can also lead to sympathetic feelings of sorrow and concern for the person's well-being [8].

Many researchers define empathy as the ability to feel and understand the other's personal world as if it was one's own, but without losing one's self. In other words, one experiences another person's emotional, behavioral and intellectual state while both individuals are completely separated. The emotional reaction and concern of an individual's feelings are demonstrated by care, sympathy, compassion and tenderness towards another person, and it derives from wanting to ease their distress. Empathy is the emotional responsiveness which an individual show to the feelings experienced by another person; the ability to identify with another's emotions and understand what they are feeling $[4,5,9]$.

Empathy is likely both dynamic, in the sense that it is a process that rapidly unfolds over time, and multifaceted, involving verbal and nonverbal emotional expressions (e.g., facial, vocalic, posture, body movement), subjective feelings (i.e., affective experience), and physiological changes [10].

Empathy consists of three components [11-13]. The emotional component Emotions are thought to play a crucial role in empathy as they are guiding thoughts and actions, as well as regulating behavior, and assist in adapting to situations $[3,14]$. That is mainly characterized by an emotional empathetic reaction to sadness, worry and anxiety. The intellectual/cognitive component is characterized by the ability to understand why, or in other words, cognitive functioning, an understanding of others $[5,15,16]$. The behavioral component that is characterized by extending help to those in need. The behavioral component considers the behavioral ability that promotes altruism [7].

Empathy is an evolved mechanism that promotes altruistic behavior. The Evolutionary theory postulates that altruistic behavior evolved for the return-benefits it bears to the performer. For return-benefits to play a motivational role, however, they need to be experienced by the organism. Motivational analyses should restrict themselves, therefore, to the altruistic impulse and its knowable consequences. Empathy is an ideal candidate mechanism to underlie so-called directed altruism, i.e., altruism in response to another's pain, need, or distress. Evidence is accumulating that this mechanism is phylogenetically ancient, probably as old as mammals and birds. Perception of the emotional state of another automatically activates shared representations causing a matching emotional state in the observer. With increasing cognition, state matching evolved into more complex forms, including concern for the other and perspective taking. Empathy-induced altruism derives its strength from the emotional stake it offers the self in the other's welfare. The dynamics of the empathy mechanism agree with predictions from kin selection and reciprocal altruism theory [7,17]. There are interconnections between emotion and cognition and executive functions [18-21]. Altruism and morality have no necessary connection. You can lead a person to act in a way that judges moral and violates his or her own moral standards. However, the challenge is to orchestrate altruistic and moral motives, so they complement one another [21].

Gauthier [22] claimed the ability to respond altruistically to another's distress is stipulated by the development of the emotional and social understanding of the child and by his self-regulation ability. The ability to control aggressive urges influences the way the child reacts to another's distress. In a study conducted on toddlers aged 1.5-3 it was found that toddlers that shared toys with their peers responded more sensitively to their distress. The level of sensitivity to peers' distress predicted reciprocity that was manifested by sharing toys and giving away objects [23].

\section{Empathy in early childhood}

Empathy plays an important role in becoming a socially competent person with meaningful social relationships [24]. The ability to act in an empathetic manner is recognized as early as in the first days after birth. Empathy is congenital; it is expressed in infancy and during childhood years [25-27]

Empathy can lead to personal distress or to empathic concern (sympathy). Empathy is constructed by an induction process during interactions. The nature of this process is sharing positive and negative emotions without losing sight of whose feelings belong to whom [28]. Moreover, it is a feature that has continuity over time $[29,30]$.

Hoffman [4,27] defined empathy development as the following:

1) Global empathy - in the first year of life children may match the emotions they witness;

2) Egocentric empathy - from the second year of life;

3) Empathy for another's feelings - in the third year of life, children become aware that other people's feelings can differ from their own;

4) Empathy for another's life condition - by late childhood.

This model has empirical support in modern day research [31]. 
Empathy may also be found with respect to entire groups of people (the poor, the oppressed, etc.) and thus transcend immediate experience. As children reach the preschool years, significant developments occur in cognitive empathy, or theory of mind abilities. There is evidence to suggest that these early dispositions toward empathy and prosocial behavior may be consistent and stable over time. By the age of five, most children realize that their own opinion is not necessarily the same as others' opinion. The children's ability to enter another person's mind and understand their needs, motives and point of view enables them to predict emotional reactions to their actions and behave accordingly $[32,33]$. The most advanced level of empathy appears in early adolescence, when awareness of social, political and economic injustice may concentrate the majority of their efforts in softening and diminishing individual or groups suffering [32].

Empathy is influenced by many factors, both intra-personal like genetics and the course of pregnancy, and inter-personal factors, that include the child's close environment, its complexity and his interactions with it. The ability to empathize develops with contributions from various biologically and environmentally based factors. These factors include genetics, facial mimicry and imitation, sub serving areas of the brain such as the mirror neuron system and the limbic system, child temperament, parenting factors such as warmth, parent-child synchrony, and other qualities of the parent-child relationship. If one or more of these factors function atypically, they may contribute to empathy deficits, such as those present in autism spectrum disorders or psychopathy, that the structure of social experience is limited or absent especially the limited quality to see another personcenteredness [34].

The awareness to other people's feelings by young children from very different cultural backgrounds suggests that empathy may be a basic human characteristic related to social adaptation [3537].

Theoretical considerations and new empirical evidence suggest, that children's development cannot simply be explained by either genes or environment, but that their interaction is important to understanding child behavior. The findings demonstrate that a molecular genetic strategy, based on genotyping of common polymorphisms and combined with a classic twin approach, provides a richer description of how genes and environment interact to shape children's behavior, and allows for the identification of differential sensitivity to parental influence. Genetic effects contributed to both change and continuity in children's empathy, whereas shared environmental effects contributed to stability and no shared environmental effects contributed to change. Empathy was associated with prosocial behavior, and this relationship was mainly due to environmental effects [31,38].

Many studies have examined how a person's tendency and ability to empathize predicts social behavior toward others [39-41]. The ability to empathize is an important part of social and emotional development, affecting an individual's behavior toward others and the quality of social relationships and promoting positive behaviors toward others and facilitating social interactions and relationships [42]. Empathy-related are predictive of children social competence and low problem behaviors [43].

Studies that examined empathy in regard to feelings [15] and social development [40] found that mutual influences exist between empathy and social behaviors [15,44-46]. It was also found that children who show more empathy to others show a less aggressive and more prosocial behaviors and understand shame and aggression as opposed to children who show less empathy $[43,47]$. Younger preschoolers were more prone to choose happy responses, whereas older preschoolers chose more adaptive behavior responses. Emotion and Self-regulation were associated with emotion and behavior responses concurrently and across time [32]. In addition, a connection between moral behavior and empathy was found - there is a connection between empathy in regard to guilt feelings [48]. Another study [49] examined whether a similar interrelation exists between emotionality observed in natural setting and emotional function in a preschool population. They found that emotionality positively predicts later emotional function. There have been numerous studies that have separately showcased advantageous outcomes associated with positive emotionality and early precursors of self-regulatory processes [16,50-52].

Empathy, both as a momentary emotional state and as a quality, is important to the development of interpersonal relationships as prediction of important social behaviors such as extending help, and therefore is very interesting in regard to developmental research.

Empathy plays an important role in moral orientation toward others but also plays a limited role if unaided by regulation, cognition and culture [5].

As for empathy and gender, a research that tested correlation between gender and empathy [53] found no gender differences in young children. In older children, it was found that girls tend to express empathy towards their gender group while boys do so in regard to the opposite sex. Females do indeed appear to be more empathic than males. They do not appear to be more adept at assessing another person's affective, cognitive, or spatial perspective.

However, there is also evidence to suggest that empathy in females may be part of a prosocial affective orientation that includes the tendency to experience guilt over harming others. However, at least in early childhood it does not appear to be part of a larger interpersonal sensitivity that includes egocentric concerns about the feelings of others toward the self. It is suggested that females may have greater tendency to imagine themselves in the other's place, whereas males have more of a set toward instrumental ameliorative action [54].

In conclusion, empathy in the research literature was examined as a genetic and developmental phenomenon, one that includes 
reference to feelings, morality, difficulties of children and culture. Many studies have examined empathy in affinity to various components in the social development of children.

Despite this rich theory, empirical work that focuses on the dynamic and multifaceted nature of children's empathy is lacking. There is very little Knowledge about connections between empathy and Empathy Intensity in children.

This study focuses on the development of the child's emotional intensity in listening to situations involving empathic situations, and the relationship between Empathy Intensity and willingness to act in empathetic situations. Measures of Empathy Intensity during an empathic event influence cardiac activity. In research literature, there are calls for models that are more sensitive to aspects of emotion and their reflection of behavior [55-58]. The present study is built on these works in examining significant differences in intensity of emotion during empathy situations in children in different ages.

\section{Method}

\section{Research questions}

1. Are there significant differences in intensity of emotion by age and by viewpoint?

2. What are the significant demographic, emotional and cognitive predictors of promoting behavior level related to children aged 4-8 in empathy-evoking situations?

\section{Research population}

The research participants included 206 children aged 4-8 years old. They were divided into three age groups (4 years old; 5-6 years old; and 7-8 years old), and by gender (girls; boys). The participants were chosen because of the researcher's access to the preschools and the preschool teachers, who agreed to cooperate and help with gathering data, and the children's parents, who gave their consent of participation in the study. Seven preschools and two classes were chosen.

\section{Research tool}

\section{ACC (Affect, Cognition, Coping)}

The questionnaire was developed based on theoretical background and a previous questionnaire [59], which has five stories in two versions - for boys and for girls.

This questionnaire underwent a long process of adjustment. The first step included eight stories, four contained positive emotions and the other four contained negative emotions. Each of the stories was followed by six questions. This version was too long for the children.

After it was given to the children by different teachers in different situations it was decided to shorten it after the children's answers were analyzed and after they were asked how frequently they encountered the situations described in the stories. The feelings: happy, sad, envy, anger and fear were chosen, the five emotions that were found to be most common in early childhood, four negative and one positive.

Following this long process, the questionnaire described five stories that raised the children's interest.

The questionnaire structure was based on previous questionnaires as well as on the research literature that claimed that in order to examine empathy it is necessary to examine the ability to identify the emotion and adjust it to the situation, and the child's ability to explain his choice [41].

The existing questionnaires were added a classification of the intensity of the chosen emotion (1-3) and addressed the willingness to act and the child's ability to explain his choice. Emoji's were chosen to describe feelings.

The stories were as follows:

Story 1: A girl likes her friend very much and invites her to come and play with her in the afternoons. One day the friend agreed to come over and the girl was very happy, prepared all the games, and even helped her mother bake a cake, but the friend never came and did not even call.

Story 2: A group of girls played in the yard. Suddenly one of the girls told everyone another girl's secret that none of them knew about, and they all laughed.

Story 3: A new girl that does not speak Hebrew very well arrived in the classroom. During reassess, everyone went outside and played, and the new girl was left standing alone.

Story 4: Two girls went with their mothers to see a play. As they entered the hall one of the girls' mother bought her candy, and the other mother did not agree to buy her daughter candy. The girl who did not get a candy stood and looked at the other girl as she was happily eating her candy.

Story 5: At the end of every school day, the parents picked their children up. One girl waited for her mother, but she never came, and the girl was left sitting and waiting.

For every story, the following six questions were asked:

1. What did the other feel like? How strongly? (intensity of emotion-the other)

2. Why did the other feel this?

3. What did the child that listened to the story feel? How strongly? (intensity of emotion-self)

4. Why did the child feel this?

5. What would you do if you witnessed something like that? (promotion behavior level)

6. Why? (cognitive level of behavior explanation)

In the first and third questions, the child was asked to choose her/his feeling from a list of five different types: anger, joy, fear, sadness and envy. The emotions were presented with smiley icons (see Illustration 1). 
The participants were asked to choose one or more suitable emotion and then to evaluate the intensity of the emotion they or the other feel. The intensity ranged from 1 - very little to 3 strong feeling.

The fifth question asked the child to choose from a list of nine options, one or more behavior/actions that could be taken: cry, think, talk, yell, be quiet, do, leave-run away, fight, make up. The possible actions were presented with smiley icons (see Illustration 2).

The actions were coded (0-3) based on their level of promoting behavior -

(0) don't know;

(1) cry, yell, fight, run away;

(2) think, be quiet;

(3) talk, do, make up.

The behaviors were divided into two categories: willingness to act positively to promote empathy, which included "think, talk, do, make-up", and actions that do not promote an empathetic process, which included "don't know, cry, yell, fight, run away". A measure based on counting the number of behaviors found in the stories was built.

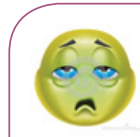

Envy

Illustration 1

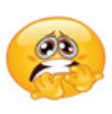

Fear

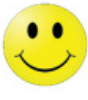

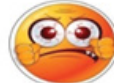

Anger
Emotions presented with smiley icons.
Do

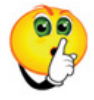

Be Quiet

\section{की}

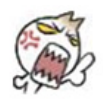

Yell
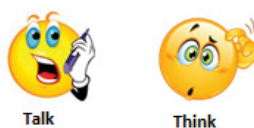

Think

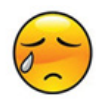

Cry

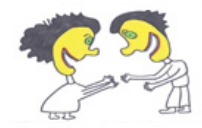

Make Up

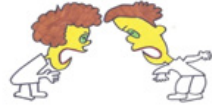

Fight

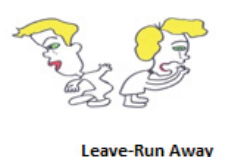

Leave-Run Away
Illustration 2 Actions presented with smiley icons.

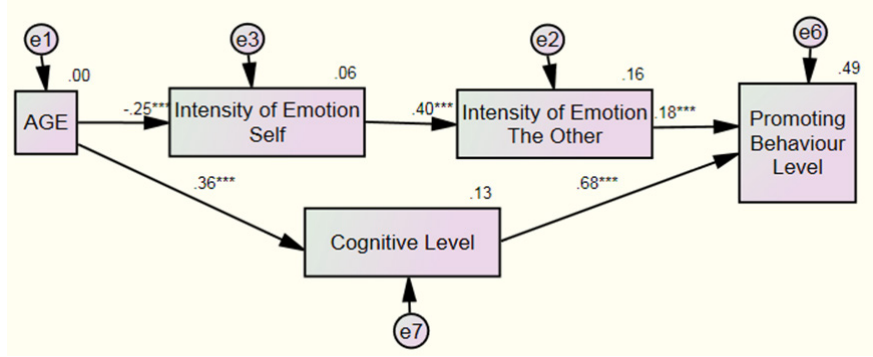

Figure 1 Optimal structural model for predicting Promoting Behavior Level.
The sixth question asked the children to explain why they chose to take the action they took. Their answers were analyzed and coded by judges according to a criteria list. Each answer received a score on a scale ranging from zero to four (zero - no explanation; one - limited delaying explanation; two - limited advancing explanation; three - extended advancing explanation; four - deep explanation) (See Table 1).

\section{Validation}

The questionnaire content validation was tested during a previous research that examined the influence of an intervention program on empathy in young children in first and second grades [60]. In this study, an explanatory factor analysis with Varimax rotation was performed to examine the construct validity of the questionnaire. The analysis indicated four distinct content worlds that match the dimensions of the Empathy questionnaire:

(1) intensity of emotion-self;

(2) intensity of emotion-the other;

(3) promotion behavior level; and

(4) cognitive level of behavior explanation.

The cumulative percentage of explained variance was $49.66 \%$. In addition, internal consistency (Cronbach's alpha) was tested in order to test the reliability of each dimension. An internal consistency coefficient was calculated for each dimension separately and revealed $\alpha_{1}=0.71 ; \alpha_{2}=0.70 ; \alpha_{3}=0.69 ; \alpha_{4}=0.77$, respectively.

\section{The research variables}

The independent variables are the children's age $(4 ; 5-6 ; 7-8)$ and gender (boys; girls).

The dependent variables are the different dimensions of empathy:

(1) intensity of emotion-self;

(2) intensity of emotion-the other;

(3) promotion behavior level; and

(4) cognitive level of behavior explanation.

All the variables were calculated by averaging the answers to each question in relation to all of the five stories.

\section{Data analysis}

The part of the study described in this paper is quantitative. The instrument was administered to 206 participants and statistical analyses were performed to:

(1) test the instrument reliability by examining its internal consistency;

(2) ascertain the instrument construct validity by using explanatory factor analysis (EFA);

(3) test the intensity of emotion by gender and age using repeated measures ANOVA test; 
(4) construct a predicting model to promoting behavior level related to children aged 4-8 in empathy-evoking situations by demographic, emotional and cognitive predictors using hierarchic regression; and

(5) construct a structural model using structural equation modeling (SEM) for refining this model.

SPSS software was used for calculating descriptive statistics and performing inferential tests. In addition, the SPSS add-on module AMOS was used for structural equation modeling.

\section{Ethics}

The Chief Science Officer in the Ministry of Education gave his approval of the questionnaire. The children's parents gave their permission for their children to participate in the research. The children remained anonymous. The preschool teachers, who are close to the children who participated in the research, are the ones who asked the children to answer the questions in different situations. This enabled the teachers to get to know each child better and help it in promoting empathetic and social aspects.

\section{Results}

The research participants included 206 children aged 4-8 years old.

Table 1 Date encoding - Open answers: Why did you do this?
Table 2 describe the research groups' distribution by age and by gender. These age groups were chosen based on the research literature that found that at the age of four a child is able to verbalize his emotions.

In relation to the research questions the results found were:

\section{Intensity of emotion values}

In order to measure children's Empathy four indices were defined. One (Intensity of Emotion) was measured twice - in relation to the other and in relation to themselves. The other two (Promoting behavior level; Cognitive level of behavior explanation) were only measured in relation to themselves. Table 3 describes the ranges, means and standard deviations of all the indices of Empathy with respect to all the study's participants.

As can be seen in Table 3, the Intensity of emotion values are ranged between one to three and the mean values are above two, suggesting that most of the children felt moderate to strong intensity of emotions regarding themselves and regarding the character in the story (the other). The mean value of the behavior that was selected in relation to the story was between limited to extension promoting behavior and indicates that most of the children chose a promoting behavior either indirectly or directly.

\begin{tabular}{|c|c|c|c|c|}
\hline $\begin{array}{c}\text { No } \\
\text { explanation }\end{array}$ & $\begin{array}{l}\text { Limited delaying } \\
\text { explanation }\end{array}$ & $\begin{array}{l}\text { Limited advancing } \\
\text { explanation }\end{array}$ & Extended advancing explanation & Deep explanation \\
\hline Do not know & $\begin{array}{l}\text { Because I do not } \\
\text { like to hear shouts }\end{array}$ & $\begin{array}{l}\text { I'd think why they } \\
\text { quarreled }\end{array}$ & $\begin{array}{l}\text { Complementing their sons thinks - what to do } \\
\text { in such a case. I would take him to the teacher } \\
\text { and talk to her about the fact that she would be } \\
\text { angry at him and I would make up their children } \\
\text { for not doing such things to him }\end{array}$ & $\begin{array}{l}\text { I would try to save money to buy the } \\
\text { polygraph to see it really or just and } \\
\text { that boy made him feel that way }\end{array}$ \\
\hline 0 & 1 & 2 & 3 & 4 \\
\hline
\end{tabular}

Table 2 Participants' distribution by age and gender.

\begin{tabular}{|c|c|c|c|c|c|}
\hline Age & $3-4$ & $5-6$ & $7-8$ & 36 & 90 \\
\hline Boys & 16 & 38 & 41 & 116 \\
\hline Girls & 22 & 53 & 77 & 206 \\
\hline Total & 38 & 91 & 77 & \\
\hline
\end{tabular}

Table 3 Means (standard deviations) and range of each empathy index ( $N=206)$.

\begin{tabular}{|c|c|c|c|}
\hline & Range & Self Mean(sd) & Other Mean(sd) \\
\hline Intensity of emotion & $1-3$ & $2.29(.65)$ & $2.44(.63)$ \\
\hline Promoting Behavior level (selected in relation to the story) & $0-3$ & $2.28(.67)$ & - \\
\hline Cognitive level of behavior explanation & $0-4$ & $2.12(.84)$ & - \\
\hline
\end{tabular}

Table 4 Intensity of emotion means by age, f and partial eta squared results.

\begin{tabular}{|c|c|c|c|c|c|}
\hline & \multicolumn{3}{|c|}{ Age } & \multirow{2}{*}{$F(2,199)$} & \multirow{2}{*}{$\eta^{2}$} \\
\hline & 3-4 Years old Mean(sd) & 5-6 Years old Mean(sd) & 7-8 Years old Mean(sd) & & \\
\hline Intensity of emotion-other & $2.84(.10)^{a, b}$ & $2.42(.06)^{a}$ & $2.31(.07)^{\mathrm{b}}$ & $9.98^{* * *}$ & .09 \\
\hline Intensity of emotion-self & $2.70(.10)^{a, b}$ & $2.26(.07)^{\mathrm{a}}$ & $2.12(.07)^{\mathrm{b}}$ & $11.11^{* * *}$ & .10 \\
\hline
\end{tabular}

Note: Identic

$* * * P \leq 0.001$ 


\section{Intensity of emotion by gender, age and viewpoint}

In order to answer the first research question and find whether there are differences in children's Emotion Intensity by Age, by Gender and by Viewpoint, we conducted multi-way repeated measures ANOVA test. The test regarded the Intensity of emotion as a dependent variable while the Viewpoint (self and other) served as within independent variable, and the Age (4 years old; 5-6 years old; and 7-8 years old), and Gender (boys and girls) served as between independent variables.

Findings revealed a significant main effect for Viewpoint ( $F$ $\left.(1,199)=9.014, p<0.01, \eta^{2}=.04\right)$ indicating significant higher Intensity of emotion for the other $(M=2.52, s d=0.644)$ then for the self $(M=2.36, s d=0.659)$. Another significant main effect was found for Age $\left(F(2,199)=16.036, p<0.001, \eta^{2}=0.14\right)$ indicating significant higher Intensity of emotion for the 4 years old children $(M=2.77, s d=0.499)$ then for the $5-6$ years old children $(M=2.34$, $s d=0.493)$ and the $7-8$ years old children $(M=2.22$, $s d=0.491)$. No significant difference was found between the latter two (5-6 and 7-8). Neither significant main effect for Gender nor double or triple interaction was found.

The results of post hoc ANOVA tests by Age for each one of the Intensity of emotion measurers separately (self and other) are presented in Table 4 and emphasize the downward trend in Intensity of emotion as children get older.

The results of post hoc pair-sample t-test by Viewpoint (self and other) for each one of the Age groups separately (4 years old; 5-6 years old; and 7-8 years old) are presented in Table 5 and highlight the increasing gap between the Intensity of emotion for the other and the self.

\section{Predicting the promoting behavior level related to} children aged 3-8 in empathy-evoking situations by demographic, emotional and cognitive predictors
In order to answer the second research question and find the predictors of promoting behavior level, we conducted hierarchic regression. The first step included the demographic variables (Gender; Age), in the second step the emotional aspect (self and other Intensity of Emotion) entered and in the third step the cognitive aspect (Cognitive level of behavior explanation) was added. Tables 6-8 present the hierarchic regression results for each step respectively.

The results of the first step as can be seen in Table 6 indicated that children's Age was significant predictor of Promoting Behavior Level while Gender was not found as significant predictor. This step as a whole was significant and accounted for $3 \%$ of the variance in Promoting Behavior Level.

In the second step, the two variables related to the Intensity of Emotion entered, the one that relates to the other in the story and the one that relates to the participants themselves.

The results of the second step, which are listed in Table 7, indicate that the Gender remains a non-significant predictor. The Age was found as significant predictor in this step as well, but in a higher level of significance. In addition, the Intensity of Emotion to the other was found as significant predictor while the Intensity of Emotion to themselves was not significant. This step as a whole was significant and accounted for $7 \%$ of the variance in Promoting Behavior Level.

In the third step, the cognitive aspect was added, meaning the cognitive level of behavior explanation entered as another predictor to the regression test.

The results in Table 8 indicate that the Gender remains a nonsignificant predictor and Age was a non-significant predictor, too. The Intensity of Emotion to the other remains a significant predictor while the Intensity of Emotion to themselves remains not significant. In addition, the cognitive aspect, meaning the Cognitive level of behavior explanation, was found significant. This step as a whole was significant and accounted for $49 \%$ of the variance in Promoting Behavior Level.

Table 5 Intensity of emotion by age and viewpoint - means and pair-sample t-test results.

\begin{tabular}{|c|c|c|c|c|c|}
\hline & Age & $\mathbf{N}$ & Character Mean (sd) & Self Mean (sd) & t-test \\
\hline \multirow{3}{*}{ Intensity of emotion } & $3-4$ & 38 & $2.83(.10)$ & $2.70(.10)$ & 1.36 \\
\hline & $5-6$ & 91 & $2.41(.06)$ & $2.26(.07)$ & $2.1^{*}$ \\
\hline & $7-8$ & 77 & $2.31(.07)$ & $2.12(.07)$ & $2.29 *$ \\
\hline
\end{tabular}

$* p<.05 ; * * * p \leq .001$

Table 6 First step of hierarchical regression: Predicting the level of promoting behavior by demographic variables.

\begin{tabular}{|c|c|c|c|c|c|}
\hline Step I & & b & Std. Err. & B & $\mathbf{t}$ \\
\hline Gender & & 0.043 & 0.094 & 0.032 & 0.458 \\
\hline Age & & 0.098 & 0.04 & 0.169 & $2.45 *$ \\
\hline $\mathrm{R}$ & $0.17^{*}$ & & & & \\
\hline$R^{2}$ & 0.03 & & & & \\
\hline $\mathrm{F}$ & $3.05^{*}$ & & & & \\
\hline df-regression & 2 & & & & \\
\hline df-residual & 203 & & & & \\
\hline
\end{tabular}

$* * \mathrm{p}<0.05 * * * \mathrm{p}<0.001$ 
The results of the first research question indicated significant relations between Intensity of Emotion-the other and Intensity of Emotion-self as well as to the participant's Age. The results of the second question indicated relations between Intensity of Emotion to the other and Promoting Behavior Level, but no significant relations between the latter and Intensity of Emotion-self as well as to the participant's Age. Therefore, it was decided to construct a structural equation model using the AMOS software. This model could represent the relations between Promoting Behavior Level and the demographic, emotional and cognitive predictors in a better way. Figure 1 exhibits the structural model with which the relations between the exogenous and endogenous variables was examined. It was chosen as the optimal model because the indicators' values suggest that there is good goodness-of-fit, $\chi^{2}(5)=6.38 ; p>0.05 ; \mathrm{RMSEA}=0.037 ; \mathrm{SRMR}=0.0372 ; \mathrm{GFI}=0.988$; $\mathrm{TLI}=0.987 ; \mathrm{NFI}=0.971 ; \mathrm{CFI}=0.993$.

The model shows that Promoting Behavior Level is predicted by two direct predictors as seen in the hierarchic regression model. The first predictor is the endogenous Cognitive level of behavior explanation and the second is the endogenous Intensity of Emotion-the other. In addition to Promoting Behavior Level direct predictors, it seems that the endogenous Intensity of Emotion-self predicts the endogenous Intensity of Emotion-the other.

More interesting predicting relations in this structural model relates to the role of the exogenous Age. We can see the significant negative relation between Age and the endogenous Intensity of Emotion-self suggesting that older children revealed lower Intensity of Emotion-self. The significant positive relation between Age and Cognitive level of behavior explanation indicate that older children have better explanations to their chosen behavior.

\section{Discussion}

The discussion deals with three findings concerning the intensity of emotion in regard to children's age and other aspects of empathy. The discussion leads to the main finding in the research - the distinction in intensity of emotion in children and the explanation of their feelings as predictor of empathetic behavior.

The results of this research questions indicated significant relations between Intensity of Emotion-the other and Intensity of Emotion-self as well as to the participant's Age.

The difference found in this research in the Intensity of Emotion of the child in regard to the other and in regard to himself, is supported by research literature and indicates that the child experiences the feelings of the other in the story while understanding that he is different from it and that he has independent feelings. This ability puts the child in the place of the other, allowing him to step into its shoes in understanding of its difficulties and emotions without losing his selfness. Moreover, the research literature indicates the child's ability from age four and up to understand the other's intentions and aspirations. At

Table 7 Second step of hierarchical regression: Predicting the level of promoting behavior by demographic variables and emotion intensity.

\begin{tabular}{|c|c|c|c|c|c|}
\hline Step II & & b & Std. Err. & B & $\mathbf{t}$ \\
\hline Gender & & 0.049 & 0.093 & 0.037 & 0.535 \\
\hline Age & & 0.122 & 0.041 & 0.212 & $2.97 * *$ \\
\hline Intensity of Emotion self & & -0.011 & 0.078 & -0.011 & -0.14 \\
\hline Intensity of Emotion-other & & 0.213 & 0.08 & 0.199 & $2.65^{* *}$ \\
\hline $\mathrm{R}$ & $0.26 * *$ & & & & \\
\hline$R^{2}$ & 0.07 & & & & \\
\hline $\mathrm{F}$ & $3.53 * *$ & & & & \\
\hline df-regression & 4 & & & & \\
\hline df-residual & 201 & & & & \\
\hline
\end{tabular}

$* * \mathrm{p}<0.05^{* * *} \mathrm{p}<0.001$

Table 8 Third step of hierarchical regression: Predicting the level of promoting behavior by demographic variables, emotion intensity and cognitive level.

\begin{tabular}{|c|c|c|c|c|c|}
\hline Step III & & b & Std. Err. & B & t \\
\hline Gender & & 0.053 & 0.068 & 0.039 & 0.781 \\
\hline Age & & -0.021 & 0.032 & -0.037 & -0.66 \\
\hline Intensity of Emotion self & & 0.039 & 0.058 & 0.037 & 0.666 \\
\hline Intensity of Emotion-other & & 0.166 & 0.06 & 0.155 & 0.701 \\
\hline Cognitive level of behavior explanation & & 0.562 & 0.043 & $12.94^{* * *}$ \\
\hline $\mathrm{R}$ & $0.70^{* * *}$ & & & \\
\hline $\mathrm{R}^{2}$ & 0.49 & & & \\
\hline $\mathrm{F}$ & $38.66^{* * *}$ & & & \\
\hline df-regression & 5 & & & \\
\hline df-residual & 200 & & & \\
\hline
\end{tabular}

\footnotetext{
$* * p<0.05 * * * p<0.001$
} 
this age, the child distinguishes between himself and the other and develops an empathetic care for the other. According to these data, it can be seen that children have "stepped out" of the situation and felt the emotions in a lower intensity than the other in the story did. This empathetic ability prevents overinvolvement that can destroy the empathetic process and causes a balance in the social situation that requires empathy [61]. The research findings validate the research literature findings in this subject.

The high Intensity of Emotion level towards the other is different between the 3-4 years old group and the 5-8 years old age group. However, no distinction was found between the 5-6 age group and the 7-8 age group. In research literature and mostly in studies related to the field of the Theory of Mind, it is claimed that during the ages of five to eight the child's ability to understand the other's needs, motives and viewpoint is developed. This ability allows the child to predict emotional reactions to his actions and behave accordingly [33] and interpret social situations and empathy situations $[62,63]$. This could be the reason for the distinction between the ages of 3-4 and the non-distinction between the ages of 5-8.

The results also indicated relations between Intensity of Emotion to the other and Promoting Behavior Level. Nevertheless, no significant relations were found between the latter and Intensity of Emotion-self as well as to the participant's age.

Prosocial behavior to a person in distress is more common than a behavior that is not prosocial in children aged 4.5-6.5 years old [64]. Children tend to choose prosocial behaviors towards the other in the stories. However, the connection between the intensity of emotion and empathy advanced behavior was not examined. Empathy motivates people to make an effort and demonstrate a prosocial behavior towards a person in distress in order to relieve his trouble. In this research, it was found that the child's intensity of emotion is in line with choosing his empathetic behavior.

This finding was supported by research literature that examined mutual connections between prosocial behavior and empathy [29,31,37]. (It was also found that prosocial behavior is increasing with age [31,37]. A research that conducted observations on children aged 3-5 while they were engaged in their routine in preschools [31,37] found that children are able to be accurate in understanding the other's emotional expression and are also able to explain their own emotions as well as the other's. However, the younger children attributed external reasons parallel to limited explanations that were found in this research to the other's emotions, while the older children, aged five, gave internal or mental reasons parallel to the extended explanations [65].

These findings support the finding in this research that emphasizes the connection between the intensity of emotion and the child's choice of empathy advanced behavior. That being the case, the Intensity of Emotion is connected to the emotional expression and to the behavioral manifestation of the emotion. Empathy is connected to emotional self-regulation and children's social skills [50] and the intensity of emotion predicts children's social behavior.

The significant positive relation between Age and Cognitive level of behavior explanation indicate that older children have better explanations to their chosen behavior.

The cognitive element is characterized by the ability to understand emotion. The emotional element and the cognitive element can be explained by the Theory of Mind, that relates to the individual's ability to understand situations and interpret them as well as recognize the other's mental situations, such as beliefs, aspirations, intentions and feelings. This ability is necessary in order to understand and predict human behavior and initiate social interactions. This ability begins to develop in infancy and in the ages 3-5 children experience a significant change in their ability to understand mental states and as a result, understand social situations. The development of the Theory of Mind has a direct connection and influence on the perception about the development of empathy and understanding of the other. Children's ability to step into the other's shoes and understand its needs, motives and viewpoint allows them to predict others' emotional reactions to their actions and behave accordingly [33].

The cognitive component of this study is reflected in the children's ability to explain the chosen emotions. This ability is affected by cognitive development. For example, research findings indicate that children aged 3-6 were expected to experience improved self-regulation. The development of self-regulation during this period is related to the child's cognitive development and the development of the language and understanding of social situations that occur within it. At these ages, children acquire the ability to use rules and strategies for action. The ability to avoid inappropriate emotional reaction also develops [66]. The development of language continues until the end of the second decade of children's lives. This development involves parallel acquisition of grammatical knowledge, structures of language and acquisition of communicative knowledge about the appropriate verbal implementation of the circumstances $[67,68]$.

\section{Conclusion}

The model in this research shows that Promoting Behavior Level is predicted by two direct predictors as seen in the hierarchic regression model as well as in the structural model. The first predictor is the endogenous Cognitive Level of Behavior Explanation and the second is the endogenous Intensity of Emotion-the other. This finding indicated the connection between empathetic behavior and children's cognitive development and their ability to separate the intensity of emotion in regard to themselves and others.

Researchers and research literature claim that empathetic ability is congenial, however, the child's environment has significant influence. This research examined the connection between the 
intensity of emotion and the child's ability to explain and choose empathetic behavior.

\section{Research Contribution}

Society consists of many individuals, different cultures and social identities with many differences between them. However, the ability to feel and understand is common to all. This ability is manifested in different intensities and expressed in different behaviors.

The results showed that different facets of empathy are more predictive of young children's showing specific kinds of changes during an empathetic event.

According to the findings in this research, investing in promoting empathy and awareness to the intensity of the child's emotion as early as in young childhood will encourage and enable to deal with and embrace empathetic behavior in the future.

The great significance given to developing empathetic abilities in young children is a well-known fact. This is also true when it comes to the knowledge that the more we implement empathetic abilities at a young age, the more we contribute to the empathetic abilities of the child in adolescence and to society as a whole. The research findings indicate that there is a connection between understanding the intensity of emotion towards the other and children's empathetic behavior in social situations. The practical implications of the findings may contribute to the focus of the educator's mediation process in the child's intensity of emotion towards the other in different social situations with the aim of regulating his emotions and contributing to his empathetic behavior.

\section{Research Limitations}

The participants were chosen because of the researchers' accessibility to this population. There were no considerations regarding participant's different levels of socioeconomic conditions, different regions in the country, origin and diversity of cultures. In addition, no comparison was made between boys and girls.

\section{References}

1. Smith-Donald R, Raver CC, Hayes T, Richardson B (2007) Preliminary construct and concurrent validity of the preschool self-regulation assessment (PSRA) for field-based study. Early Child Res Q 22: 173187.

2. Jahromi LB, Stifter CA (2008) Individual differences in preschoolers' self-regulation and theory of mind. Merrill Palmer Q 54: 125-150.

3. Cole PM, Martin SE, Dennis TA (2004) Emotion regulation as a scientific construct: methodological challenges and directions for child developmental research. Child Dev 75: 317-333.

4. Hoffman ML (2000) Empathy and moral development. Cambridge University Press, p: 331.

5. Maibom HL (2014) Empathy and morality. NY: Oxford University Press, p: 320.

6. Eisenberg N, Spinrad T, Morris A (2014) Empathy related responding in children. In: Handbook of moral development (Killen M, Smetana $J 2^{\text {nd }}$ Edn). Mahwah, NJ: Erlbaum, pp: 184-207.

7. de Waal FBM (2008) Putting the altruism back into altruism: The evolution of empathy. Annu Rev Psychol 59: 279-300.

8. Eisenberg N, Eggum ND (2009) Empathic responding: sympathy and personal distress. In: The social neuroscience of empathy (Decety J, Ickes W Edn). Cambridge, MA: MIT Press, pp: 63-88.

9. Davis $\mathrm{MH}$ (1983) Measuring individual differences in empathy: evidence for a multidimensional approach. J Pers Soc Psychol 44: 113-126.

10. Hastings PD, Miller JG, Kahle S, Zahn-Waxler C (2014) The neurobiological bases of empathic concern for others. In: Handbook of moral development (Killen M, Smetana J $2^{\text {nd }}$ Edn). Mahwah, NJ: Erlbaum, pp: 411-434.

11. Dadds MR, Hunter K, Hawes DJ, Frost ADJ, Vassallo S, et al. (2008) A measure of cognitive and affective empathy in children using parent ratings. Child Psychiatry Hum Dev 39: 111-122.

12. Herba CM, Landau S, Russell T, Ecker C, Phillips ML (2006) The development of emotion-processing in children: Effects of age, emotion, and intensity. J Child Psychol Psychiatry 47: 1098-1106.

13. Jackson PL, Brunet E, Meltzoff AN, Decety J (2006) Empathy examined through the neural mechanisms involved in imagining how I feel versus how you feel pain. Neuropsychologia 44: 752-761.

14. Lehtonen A, Howie E, Trump D, Hudson SM (2012) Behavior in children with neurofibromatosis type 1: Cognition, executive function, attention, emotion, and social competence. Dev Med Child Neurol 55: 111-125.

15. Bassett HH, Denham SA, Mincic M, Graling K (2012) The structure of preschoolers' emotion knowledge: model equivalence and validity using a structural equation modeling approach. Early Educ Dev 23: 259-279.

16. Denham SA (2006) Social-emotional competence as support for school readiness: what is it and how do we assess it. Early Educ Dev 17: $57-89$

17. Post SG, Underwood LG, Schloss JP, Hurlbut WB (2002) Altruism and altruistic love: science, philosophy, \& religion in dialogue. Oxford University Press, pp: 28.

18. Blankson AN, O'Brien M, Leerkes EM, Marcovitch S, Calkins SD, et al. (2013) Developmental dynamics of emotion and cognition processes in preschoolers. Child Dev 84: 346-360.

19. Blair JR, Perschardt KS (2002) Empathy: a unitary circuit or a set of dissociable neuro-cognitive systems? Behav Brain Sci 25: 27-28.

20. Blair C, Diamond A (2008) Biological processes in prevention and intervention: the promotion of self-regulation as a means of preventing school failure. Dev Psychopathol 20: 899-911. 
21. Batson DC (2014) Empathy-induced altruism and morality. In: Empathy and morality (Maibom HL Edn). N.Y: Oxford University Press, pp: 41-58.

22. Gauthier $Y$ (2003) Infant mental health as we enter the third millennium: can we prevent aggression? Infant Ment Health J 24: 296-308.

23. Hay DF, Castle J, Davies L, Demetriou H, Stimson CA (1999) Prosocial action in very early childhood. J Child Psychol Psychiatry Allied Discipl 40: 905-916.

24. McDonald NM, Messinger DS (2011) The development of empathy: how, when and why. In: Free will, emotion, and moral actions: Philosophy and neuroscience in dialogue (Acerbi A, Lombo JA, Sanguineti JJ Edn). Rome: Pontificia University de la Santa Croce, p: 35.

25. Ginsburg HJ, Ogletree SM, Silakowski TD, Bartrls RD, Burk SL, et al. (2003) Young children's theories of mind about empathic and selfish motives. Soc Behav Pers 31: 237-244.

26. Hoffman ML (1984) Empathy, its limitations, and its role in a comprehensive moral theory. In: Morality, moral behavior, and moral development (Kurtinez WM, Gewritz JL Edn). NY: Wiley, pp: 283-302.

27. Hoffman ML (1991) Empathy, social cognition, and moral action. In: Handbook of moral behavior and development (Kurtinez WM, Gewritz JL Edn). Lawrence Erlbaum Associates, Inc, pp: 275-301.

28. Decety J, Meyer M (2008) From emotion resonance to empathic understanding: a social developmental neuroscience account. Dev Psychol 20: 1053-1080.

29. Roberts W, Strayer J, Denham S (2014) Empathy, anger, guilt: emotions and prosocial behaviour. Can J Behav Sci 46: 465-474.

30. Volbrecht MM, Lemery-Chalfant K, Aksan N, Zahn-Waxler C, Goldsmith HH (2007) Examining the familial link between positive affect and empathy development in the second year. J Genet Psychol 168: $105-129$.

31. Knafo A, Zahn-Waxler C, Van Hulle C, Robinson J, Rhee SH (2008) The developmental origins of a disposition towards empathy: genetic and environmental contributions. Emotion 8: 737-752.

32. Denham SA, Bassett HH, Way E, Kalb S, Warren-Khot H, et al. (2014) How would you feel? What would you do? Development and understandings of preschoolers' social information processing. $J$ Early Child Res 28: 182-202.

33. Goldstein TR, Winner E (2012) Enhancing empathy and theory of mind. J Cogn Dev 13: 19-37.

34. Andrews K, Gruen L (2014) Empathy in other apes. In: Empathy and morality (Maibom HL Edn). N.Y: Oxford University Press, pp: 193-210.

35. Borke H (1973) The development of empathy in Chinese and American children between three and six years of age: a crossculture study. Dev Psychol 9: 102-108.

36. Knafo A, Plomin R (2006) Parental discipline and affection and children's prosocial behavior: genetic and environmental links. J Pers Soc Psychol 90: 147-164.

37. Roth-Hanania R, Davidov M, Zahn-Waxler C (2011) Empathy development from 8 to 16 months: early signs of concern for others. Infant Behav Dev 34: 447-458.

38. Knafo A, Israel S, Ebstein RP (2011) Heritability of children's prosocia behavior and differential susceptibility to parenting by variation in the dopamine receptor D4 gene. Dev Psychopathol 23: 53-67.
39. Bruchkowrsky M (1992) The development of empathic cognition in middle and early childhood. In: The mind's staircase: exploring the conceptual underpinnings of children's thought and knowledge (Case R Edn). Hillsdale, NJ: Lawrence Erlbaum Associates, pp: 153170.

40. Edwards A, Eisenberg N, Spinrad TL, Reiser M, Eggum-Wilkens ND, et al. (2015) Predicting sympathy and prosocial behavior from young children's dispositional sadness. Soc Dev 24: 76-94.

41. Strayer J, Roberts WL (2004) Children's anger, emotional expressiveness, and empathy: relation with parents' empathy, emotional expressiveness, and parenting practices. Social Dev 13 : 229-254.

42. Marion M (2003) Guidance of young children ( $6^{\text {th }}$ Edn). Columbus $\mathrm{OH}$ : Merrill Prentice, p: 394.

43. Spinrad TL, Eisenberg N (2014) Empathy and morality: a development psychology perspective. In: Empathy and morality (Maibom HL Edn). Oxford University Press 3: 59-70.

44. Moreno A, Klute M, Robinson J (2008) Relational and individual resources as predictors of empathy in early childhood. Social Dev 17: 613-637.

45. Diesendruck G, Ben- Eliyahu A (2006) The relationships among social cognition, peer acceptance, and social behavior in Israeli kindergarteners. Int J Behav Dev 30: 137-147.

46. Zhou Q, Eisenberg N, Losoya SH, Fabes RA, Reiser M, et al. (2002) The relations of parental warmth and positive expressiveness to children's empathy-related responding and social functioning: a longitudinal study. Child Dev 73: 893-915.

47. Finddlay DC, Girardi A, Coplan RJ (2006) Links between empathy, social behavior, and social understanding in early childhood. Early Child Res Q 21: 347-359.

48. Aksam N, Kochnaska G (2005) Conscience in childhood: old questions, new answers. Dev Psychol 41: 506-516.

49. Ferrier DE, Bassett HH, Denham SA (2014) Relations between executive function and emotionality in preschoolers: exploring a transitive cognition-emotion linkage. Front Psychol 5: 487.

50. Denham SA, Blair KA, DeMulder E, Levitas J, Sawyer K, et al. (2003) Preschool emotional competence: Pathway to social competence. Child Dev 74: 238-256.

51. Denham SA, Kalb SC, Way E, Warren-Khot HK, Rhoades BL, et al. (2013) Social and emotional information processing in preschoolers: Indicator of early school success? Early Child Dev Care 183: 667-688.

52. McClelland MM, Ponitz CC, Messersmith EE, Tominey S (2010) Selfregulation: the integration of cognition and emotion. In: Handbook of lifespan human development, 4: Cognition, biology, and methods (Lerner R (Series Edn) \& Overton W (Vol. Edn)). Hoboken, NJ: Wiley, pp: 509-553.

53. Bryant B (1982) An index of empathy for children and adolescents. Child Dev 53: 413-425.

54. Hoffman M, Levine L (1977) Early sex differences in empathy. Psychol Bull 84: 712-722.

55. Brooker RJ, Buss KA (2010) Dynamic measures of RSA predict distress and regulation in toddlers. Dev Psychobiol 52: 372-382.

56. Burt KB, Obradovi CJ (2013) The construct of psychophysiological reactivity: statistical and psychometric issues. Dev Rev 33: 29-57. 
57. Fortunato CF, Gatzke-Kopp LM, Ram N (2013) Associations between respiratory sinus arrhythmia reactivity and internalizing and externalizing symptoms are emotion specific. Cogn Affect Behav Neurosci 13: 238-251.

58. Miller JG, Chocol C, Nuselovici JN, Utendale WT, Simard M, et al. (2013) Children's dynamic RSA change during anger and its relations with parenting, temperament, and control of aggression. Biol Psychol 92: 417-425.

59. Shapira R (2015) Repeated readings of a book for kindergarten children: change, stability in mother-child discourse, and prediction of the child's emotional-social understanding. Thesis for the title of Doctor of Philosophy, Tel Aviv University (In Hebrew).

60. Russo-Zimet G, Sagee R (2017) Empathy in first and second year in school: the effect of intervention program on children's empathic ability. 5: 18-51.

61. Kaniel S (2013) Empathy in education: education with love. Tel-Aviv: Mofet Institute.
62. Hughes C, Leekam S (2004) What are the links between theory of mind and social relations? Review, reflections and new directions for studies of typical and atypical development. Soc Dev 13: 590-619.

63. Harwood MD, Farrar MJ (2006) Conflicting emotions: the connection between affective perspective taking and theory of mind. Dev Psychol 24: 401-418.

64. Feldman SR (2016) Child development ( $7^{\text {th }}$ Edn). U.S.A: Pearson.

65. Fabes RA, Eisenberg N, McCormick SE, Wilson MS (1988) Preschoolers' attributions of the situational determinants of others' naturally occurring emotions. Dev Psychol 24: 375-385.

66. Eisenberg L, Spinard, TL (2004) Emotion-related regulation: sharpening the definition. Child Dev 75: 334-339.

67. Owens RE (2008) Language development. (7 $7^{\text {th }}$ Edn). New York: Macmillan.

68. Eisenberg N (2000) Emotion, regulation, and moral development. Ann Rev Psychol 51: 665-697. 